\title{
Right ventricular outflow tract reconstruction with a polytetrafluoroethylene monocusp valve: A twelve-year experience
}

John W. Brown, MD, Mark Ruzmetov, MD, PhD, Palaniswamy Vijay, PhD, MPH, Mark D. Rodefeld, MD, and Mark W. Turrentine, MD

From the Section of Cardiothoracic Surgery, James Whitcomb Riley Hospital for Children and Indiana University School of Medicine, Indianapolis, Ind.

John Brown reports consulting and lecture fees from CryoLife and consulting fees and graft support from Medtronic.

Read at the Thirty-second Annual Meeting of the Western Thoracic Surgical Association, Sun Valley, Idaho, June 21-24, 2006.

Received for publication July 7, 2006; revisions received Dec 15, 2006; accepted for publication Dec 18, 2006.

Address for reprints: John W. Brown, MD, Section of Cardiothoracic Surgery, Indiana University School of Medicine, 545 Barnhill Dr., EH 215, Indianapolis, IN, 46202-5123 (E-mail: jobrown@iupui.edu).

J Thorac Cardiovasc Surg 2007;133:1336-43 $0022-5223 / \$ 32.00$

Copyright $\odot 2007$ by The American Association for Thoracic Surgery

doi:10.1016/j.jtcvs.2006.12.045
Objective: Transannular patching of the right ventricular outflow tract results in pulmonary insufficiency. Biologic monocusp valves prevent early pulmonary insufficiency but usually become nonfunctional in less than 1 year. Polytetrafluoroethylene monocusp leaflets demonstrated favorable characteristics in our animal studies and have been applied to a variety of right ventricular outflow tract reconstructions at our institution.

Methods: From 1994 through 2006, 192 patients (mean age, $3.3 \pm 5.0$ years) underwent right ventricular outflow tract reconstruction with a polytetrafluoroethylene monocusp valve (192 patients; 202 implants). Intraoperative, early postoperative, and late follow-up echocardiographic data (mean interval, $4.9 \pm 3.1$ years; range, 6 months to 12 years) were retrospectively obtained to compare clinical outcomes among three preoperative diagnostic groups: patients undergoing initial repair of tetralogy of Fallot or pulmonary atresia/ventricular septal defect (group I), patients undergoing redo right ventricular outflow tract procedures (group II), and patients undergoing complex initial repairs (group III).

Results: There were 4 early and 5 late deaths $(9 / 192 ; 5 \%)$. The difference between the preoperative and postoperative peak right ventricular outflow tract gradients was significant $(71.2$ vs $23.1 ; P<.0001)$. Twenty-five $(14 \%)$ patients had mild-tomoderate right ventricular outflow tract stenosis at one or more locations proximal and/or distal to the monocusp patch (mean gradient, $44.7 \pm 20.3 \mathrm{~mm} \mathrm{Hg}$ ). Freedom from increased pulmonary insufficiency greater than moderate was $86 \%$ at 1 year, $68 \%$ at 5 years, and $48 \%$ at 10 years. Twenty-five patients have undergone 35 reoperations $4.2 \pm 3.1$ years (range, 3 months to 10 years after initial repair). Kaplan-Meier freedom from reoperation was $96 \%, 89 \%$, and $82 \%$ at 1, 5, and 10 years. Freedom from reoperation in group II (69\%) was significantly different from group I $(88 \% ; P=.01)$ and from group III $(90 \% ; P=.02)$, but there was no difference between groups I and III.

Conclusions: Use of a polytetrafluoroethylene monocusp valve prevents early and significantly reduces midterm pulmonary insufficiency. It is relatively inexpensive, easy to construct, and remains free from significant stenosis in the majority of patients. We have not witnessed significant calcification or pulmonary embolization, and the only antithrombic agent used has been low-dose aspirin.

$\mathrm{T}$ he surgical management of patients with tetralogy of Fallot (TOF) and significant right ventricular outflow tract (RVOT) obstruction at the valve level, who are not candidates for a valve-sparing repair, has historically been conducted in one of two ways: (1) transannular patch or (2) valved conduit insertion. The advantages of a transannular patch are that it relieves right ventricular (RV) hypertension immediately and the RVOT usually grows proportionally with the 


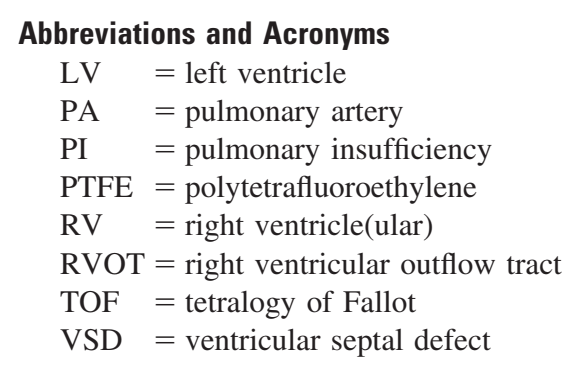

child. Reoperation for RVOT stenosis is generally uncommon. The disadvantage of the transannular patch is the sudden hemodynamic conversion of an obstructed, pressureloaded RV to a volume-loaded RV, which causes temporary and/or delayed RV dysfunction. The chronic volume overload of the RV and resultant ventricular dysfunction may necessitate late pulmonary valve insertion. ${ }^{1}$

The advantage of the valved conduit option is that it yields initially a nearly competent pulmonary valve. Conduit insertion is particularly useful in patients who have peripheral unrepaired pulmonary stenosis or elevated pulmonary vascular resistance. The obvious disadvantages of currently available valved conduits are their lack of durability owing to shrinkage, lack of growth, and/or early valvular dysfunction. These unsolved problems are manifested by the allograft conduit that became popular in the United States during the mid-1980s. Pulmonary homografts have remained popular to the present despite freedom from reoperation of only $50 \%$ at 5 years in patients undergoing a non-Ross RVOT conduit repair., ${ }^{2,3}$

An attractive alternative strategy for many years has been the creation of a monocusp RVOT patch, which has the potential advantages and lacks the disadvantages of both a transannular patch and a homograft valve conduit in certain patient populations. The monocusp RVOT patch can be created with autologous or bovine pericardium, ${ }^{4,5}$ allograft pulmonary valve cusp, ${ }^{6}$ or the (off label) use of a polytetrafluoroethylene (PTFE) membrane (0.1-mm PTFE patch; W. L. Gore \& Associates, Inc, Flagstaff, Ariz) traditionally used for pericardial closure. ${ }^{7-9}$ All types of monocusps have shown, particularly in the immediate postoperative period, to significantly reduce or prevent pulmonary insufficiency (PI). ${ }^{10}$

The elimination of PI is associated with faster recovery of RV function, a lower central venous pressure, and less postoperative chest tube drainage. ${ }^{10}$ Construction of a pericardial or PTFE monocusp is simple, relatively inexpensive, and reproducible. Allograft pulmonary valve cusps are usually more expensive and more difficult to custom fit into the RVOT. The potential disadvantage of a monocusp patch in comparison with insertion of a pulmonary valve or valved conduit is that, at least in some patients, PI recurs more quickly and completely if the monocusp sticks in the open position, as has been reported with biologic monocusps. ${ }^{6}$ Recurrent stenosis at the level of the monocusp is rarely seen with any monocusp RVOT patch. ${ }^{6,9}$

The goal of this retrospective review is to update our previous experience with the PTFE monocusp patch ${ }^{9}$ and to determine its effects in relieving and preventing RVOT stenosis and regurgitation in three groups of patients: patients undergoing initial repair of TOF or pulmonary atresia/ ventricular septal defect (VSD) (group I), patients undergoing redo-RVOT procedures (group II), and patients with complex initial RVOT reconstructions (group III).

\section{Patients and Methods \\ Study Patients}

Since 1994, 306 patients have undergone primary repair of TOF in our institutions: $46 \%$ of them underwent valve preservation surgery (without any patching, only pulmonary artery [PA] augmentation, only RVOT patch reconstruction, or both), $4 \%$ underwent conduit insertion (patients with concomitant absent pulmonary valve syndrome or patients with an important coronary artery crossing the RVOT), and 50\% underwent RVOT transannular patching (93\% of them with a PTFE monocusp). Between June 1994 and April 2006, 192 patients with severe RVOT obstruction underwent reconstruction of the RVOT with a transannular patch with a PTFE monocusp valve at James Whitcomb Riley Hospital for Children, Indianapolis, Indiana. One hundred seven $(56 \%)$ patients were girls and $85(44 \%)$ were boys. Ages ranged from 6 days to 35 years (mean, $3.3 \pm 5.0$ years) and weights ranged from 4.9 to $83 \mathrm{~kg}$ (mean, $14.0 \pm 14.2 \mathrm{~kg}$ ).

The initial preoperative diagnoses and diagnostic groups they were assigned are shown in Table 1. Forty-six (24\%) patients had had prior cardiac operations, which included repair of the RVOT. Twenty-nine of these 46 patients had had RV-PA conduits before implantation of a PTFE monocusp valve, and they included pulmonary homografts $(n=15)$, aortic homografts $(n=11)$, nonvalved Dacron tube graft $(n=2)$, and Dacron graft with a porcine valve $(n=1)$. Six patients underwent initial transannular patching without monocusp insertion.

Table 1 shows the characteristics of the three groups that were compared. Group I $(n=121)$ was the infant or young child undergoing initial repair of TOF or VSD with pulmonary atresia. Group II $(\mathrm{n}=35)$ was the older child who required reoperation for recurrent RVOT stenosis or regurgitation after initial repair with a nonvalved transannular patch or RV-PA conduit. Group III ( $\mathrm{n}=$ 36) was a more varied and complex group undergoing initial repair for TOF with absent pulmonary valve syndrome $(n=6)$, TOF or double-outlet right ventricle with atrioventricular septal defect $(\mathrm{n}=7)$, TOF with discontinuous pulmonary arteries $(\mathrm{n}=3)$, double-outlet right ventricle $(\mathrm{n}=8)$, severe PI after balloon pulmonary valvotomy $(n=6)$, pulmonary stenosis after arterial switch operation $(n=4)$, PI after complete repair of atrioventricular septal defect $(n=1)$, and initial truncus arteriosus repair $(n=1)$. Three patients with pulmonary atresia and VSD underwent RVOT reconstruction without VSD closure owing to hypoplastic PAs. 
TABLE 1. Initial preoperative diagnosis

\begin{tabular}{|c|c|}
\hline Diagnosis & $\begin{array}{r}\text { No. of } \\
\text { patien }\end{array}$ \\
\hline \multicolumn{2}{|l|}{$\begin{array}{l}\text { Group I ( } n=121) \text { : Patients with initial repair of TOF, } \\
\text { PA/VSD }\end{array}$} \\
\hline TOF & 103 \\
\hline PA/VSD & 18 \\
\hline \multicolumn{2}{|l|}{$\begin{array}{l}\text { Group II ( } \mathrm{n}=35 \text { ): Patients with redo RVOT } \\
\text { procedures }\end{array}$} \\
\hline Truncus arteriosus & 16 \\
\hline TOF & 6 \\
\hline PA/VSD & 6 \\
\hline DORV & 5 \\
\hline$s / p$ Ross procedure & 2 \\
\hline \multicolumn{2}{|l|}{$\begin{array}{l}\text { Group III ( } \mathrm{n}=36 \text { ): Complex patients with initial } \\
\text { RVOT repair }\end{array}$} \\
\hline DORV & 8 \\
\hline TOF/AVSD & 7 \\
\hline TOF/APVS & 6 \\
\hline PI or PS, $s / p$ balloon pulmonary valvotomy & 6 \\
\hline D-TGA/Taussig-Bing anomaly, s/p switch operation & 4 \\
\hline TOF/discontinuous pulmonary arteries & 3 \\
\hline Truncus arteriosus & 1 \\
\hline $\mathrm{PI}, \mathrm{s} / \mathrm{p}$ AVSD repair & 1 \\
\hline Total & 192 \\
\hline
\end{tabular}

$A P V S$, Absent pulmonary valve syndrome; $A V S D$, atrioventricular septal defect; DORV, double-outlet right ventricle; $D-T G A$, dextro-transposition of the great arteries; $P A$, pulmonary atresia; $P I$, pulmonary insufficiency; $P S$, pulmonary stenosis; $R V O T$, right ventricular outflow tract; $s / p$, status post; $T O F$, tetralogy of Fallot; VSD, ventricular septal defect.

All PTFE RVOT repairs were performed with a standard PTFE monocusp valve construction technique as previously described. ${ }^{9,11}$ The monocusp valve is tailored and inserted first to get appropriate width and length. The outflow tract patch is then inserted with a second suture line. Assignment of patients to a particular surgeon was random and without preference. Patients with defects that included an intact pulmonary annulus were evaluated in the operating room. When possible, an aggressive pulmonary valvotomy was performed, the annulus was measured with a Hegar dilator, and the pulmonary valve was spared. In patients with moderateto-severe hypoplasia of the annulus (generally less than a -2 $\mathrm{Z}$-value), a postrepair RVOT gradient measuring greater than 30 $\mathrm{mm} \mathrm{Hg}$, or a postrepair RV pressure greater than $80 \%$ of systemic pressure, a transannular repair was performed. ${ }^{5}$

After obtaining approval from our institutional review board, we performed a retrospective review of medical records with regard to initial cardiac diagnosis, pathophysiologic findings, surgical treatment, and hospital mortality. Data from outpatient visits and from patients who died after hospital discharge were obtained from physicians, hospital records, or death certificates. Medical records and clinical charts were reviewed for all PTFE monocusp valve recipients including operative records as well as preoperative and postoperative catheterization and echocardiography data. Data collected from the operative admission included diagnosis, previous operative procedures, age, sex, and weight at operation. Patient follow-up data were obtained from hospital and clinic visit records. Follow-up information was available within 2 calendar years for $96 \%$ of surviving patients. Echocardiography data, derived by continuous-wave Doppler echocardiography, were recorded from serial studies and used to quantitate postoperative PI. Evaluation of the PTFE monocusp valve's competency and relief of pulmonary outflow tract obstruction included RV systolic pressure, RV-PA gradient, tricuspid regurgitation, and degree of PI. An end-diastolic dimension of the right and the left ventricles (RV and LV) by cardiac magnetic resonance imaging has only recently become available at our institution and was performed on selected patients. Echocardiographic assessment of the PTFE monocusp valve was reported only for patients beyond 6 months after implant, and PI was divided into three grades: trace-to-mild (trace, trace-to-mild, mild), mild-to-moderate (regurgitation flow image confined within the conduit), and moderate-to-severe (moderate, moderate-tosevere, severe; regurgitation flow image extending into the sinus portions of the RV). In the same patient subset, Doppler interrogation was applied to detect the maximal flow velocity across the RVOT reconstruction. The pressure gradient was estimated by the maximal flow velocity according to the Bernoulli equation.

\section{Statistical Analysis}

Variables including demographics, diagnosis, previous palliative procedures, types of previous RVOT reconstruction, conduit type and size, type of RVOT disease, need for postoperative extracorporeal membrane oxygenation, ratio between the end-diastolic dimensions of the RV and $\mathrm{LV}$ for selected patients, tricuspid insufficiency, RV pressure, and operative procedure-related variables were assessed by univariate analysis with the $\chi^{2}$ test and multivariate logistic regression analysis. In the analysis of risk factors for early death, variables with significant levels of 0.1 in univariate analysis were submitted to a multivariate logistic regression model. Kaplan-Meier analysis was used for the actuarial survival and freedom from reoperation rate. Differences in survival curves were assessed by log-rank test. All analyses were performed with SPSS statistical software (SPSS, Inc, Chicago, Ill). Early mortality was defined as death during initial hospitalization or within 30 days of operation. Any deaths later than that were defined as late mortality. In this series, all early deaths occurred during the initial hospitalization and all late deaths occurred after discharge from the initial hospitalization.

\section{Results}

\section{Clinical Outcomes}

There were a total of 9 deaths (5\%) with 4 early and 5 late deaths. Three late deaths occurred during the first year after the operation, one 2 years later, and one 8 years after the initial operation. The mean follow-up time is $4.9 \pm 3.1$ years (range, 6 months to 12 years). The mean intensive care unit stay was 5.8 days and the length of hospital stay was 9.1 days. Details of early and late deaths are shown in Table 2. Univariate and multivariate analysis demonstrated the diagnosis of TOF plus absent pulmonary valve $(P=.03)$ and the need for postoperative extracorporeal membrane oxygenation $(P=.002)$ as the two most sensitive predictors of early mortality in patients with PTFE monocusp RVOT 
TABLE 2. Cause of early or late deaths $(n=9)$

\begin{tabular}{llrllll}
\hline No. & \multicolumn{1}{c}{ Diagnosis } & Age & Time of death & Cause of death & Genetic syndrome & Relationship to PTFE monocusp \\
\hline 1 & TOF/PA & $9 \mathrm{mo}$ & Late $(3 \mathrm{mo})$ & Pneumonia & Yes (Down) & No \\
2 & TOF & $14 \mathrm{mo}$ & Late $(7 \mathrm{mo})$ & Respiratory distress & Yes (Down) & No \\
3 & TOF & $9 \mathrm{mo}$ & Early $(30 \mathrm{~d})$ & Sepsis & No & No \\
4 & TOF/RVOT conduit & $7 \mathrm{mo}$ & Late $(2 \mathrm{y})$ & Pneumonia & No \\
5 & TOF/APV & $6 \mathrm{~d}$ & Early $(29 \mathrm{~d})$ & LCO & No & No \\
6 & TOF/APV & $2 \mathrm{mo}$ & Early $(5 \mathrm{~d})$ & LCO & No & No \\
7 & TOF/RPA atresia & $3 \mathrm{yrs}$ & Early $(5 \mathrm{~d})$ & LCO & Yes (B-K) & No \\
8 & PA/IVS & $5 \mathrm{mo}$ & Late $(4 \mathrm{y})$ & Noncardiac & Yes (DiGeorge) & \\
9 & TA & $7 \mathrm{wk}$ & Late $(1 \mathrm{y})$ & Sepsis & & No
\end{tabular}

$A P V$, Absent pulmonary valve; $B-K$, Beckwith-Wiedelmann; IVS, intact ventricular septum; LCO, low cardiac output; PA, pulmonary atresia; PTFE, polytetrafluoroethylene; $R P A$, right pulmonary artery; $R V O T$, right ventricular outflow tract; $T A$, truncus arteriosus; TOF, tetralogy of Fallot.

reconstruction. Overall survivals estimated by the KaplanMeier method including early mortality were $96 \%$ at 1 and 5 years and $95 \%$ at 10 years (Figure 1). Overall survivals in groups I, II, and III at 10 years were 98\%, 97\%, and 88\%, respectively. Group III (complex initial repair) had a higher mortality, which was significantly different from group I $(P=.01)$ but not group II $(P=.21)$.

Postoperative low cardiac output syndrome occurred in 6 patients $(6 / 192 ; 3 \%)$ and all required postoperative extracorporeal membrane oxygenation. Two patients died (early death described above). The other 4 patients were successfully weaned from extracorporeal membrane oxygenation. Additional morbidity included delayed sternal closure (9 days) in 1 patient, pleural effusion in 1 patient, and complete heart block requiring pacemaker insertion in 4 patients.

\section{Reoperations}

Thirty-five reinterventions were required after PTFE monocusp RVOT reconstruction in 25 of 188 (13\%) early survivors. The monocusp was replaced with an RV-PA conduit $(\mathrm{n}=13)$, redo PTFE monocusp valve replacement $(\mathrm{n}=10)$, surgical angioplasty of branch pulmonary stenosis (left or right $)(\mathrm{n}=6)$, stent placement $(\mathrm{n}=2)$, delayed VSD closure $(\mathrm{n}=3)$, and RVOT patch augmentation below an anomalous left anterior descending coronary artery $(n=1)$. Sixteen, 8, and 1 patient have had 1,2, or 3 reinterventions,

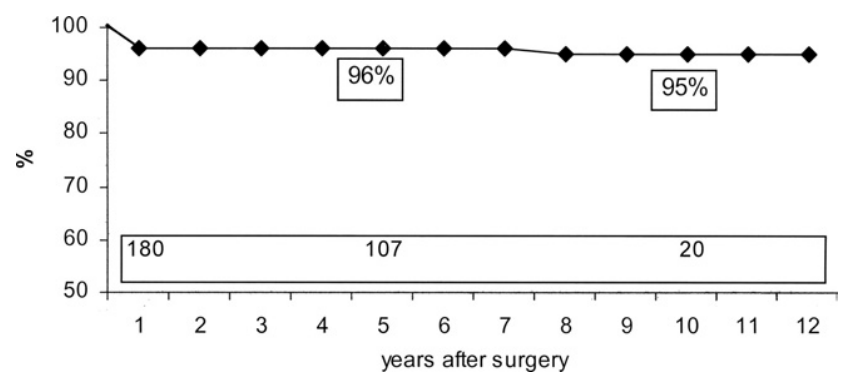

Figure 1. Kaplan-Meier estimated 12-year survival, including hospital mortality. respectively. The average time to reintervention after PTFE monocusp placement was $4.2 \pm 3.1$ years (range, 3 months to 10 years). Mean age at reintervention was $8.0 \pm 6.5$ years (range, 18 months to 28 years).

At reoperation, all patients had some degree of PTFE monocusp regurgitation. It was graded as trace-to-mild in 10 , mild-to-moderate in 9 , and moderate-to-severe in 6 patients. Seventeen of the 25 patients reoperated on after PTFE monocusp insertion had a combination of residual RVOT obstruction and monocusp insufficiency. Residual RVOT stenosis was usually multilevel and was rarely at the level of the monocusp. It usually occurred in younger, smaller infants with a significant degree of RVOT hypoplasia at the time of initial repair. Eight patients had branch PA stenosis and most had some degree of infundibular obstruction. The peak systolic gradient across the RVOT before reintervention in the 25 patients undergoing reinterventions of the PTFE monocusp was $44.7 \pm 20.3 \mathrm{~mm} \mathrm{Hg}$ (range, $10-85 \mathrm{~mm} \mathrm{Hg}$ ), as measured by preoperative echocardiography. At reoperation, 13 patients had their monocusp converted to a biologic valved conduit and 10 had a larger PTFE monocusp outflow patch inserted. Replacement conduit types were as follows: bovine jugular vein conduit (Contegra; Medtronic, Inc, Minneapolis, Minn; $\mathrm{n}=8$ ), pulmonary homograft (CryoLife, Inc, Kennesaw, Ga; $\mathrm{n}=$ 3), and a stentless porcine aortic root (Medtronic Freestyle; Medtronic, Inc; $n=2$ ). Eight patients underwent surgical angioplasty of the right and/or left PAs with PTFE patches $(n=6)$ or stent placement $(n=2)$ owing to branch PA stenosis.

Eight of 26 patients had had a previous RVOT reconstruction (before PTFE monocusp) (18\%, 8/44 survivors) and 17 procedures were in patients without any operation before PTFE monocusp insertion (12\%, 17/144 survivors; $P=.08$ ). Univariate and multivariate analysis showed the diagnosis of TOF plus absent pulmonary valve $(P=.005)$ and higher initial postoperative RV systolic pressure $(P=$ $.05)$ as the strongest predictors for reoperation. Kaplan- 


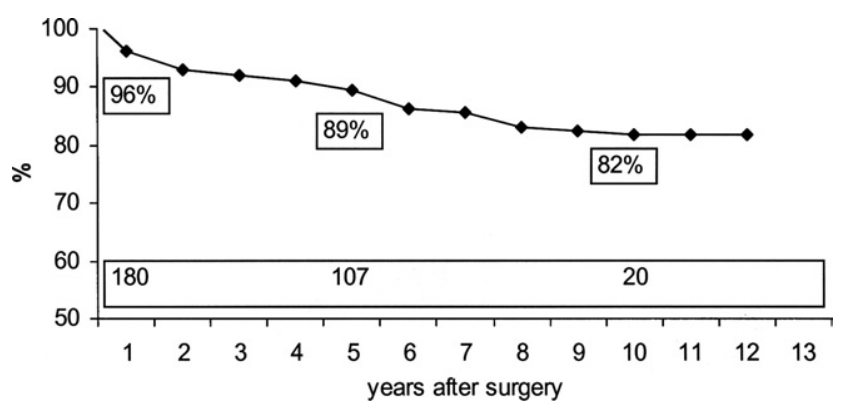

Figure 2. Kaplan-Meier estimated 12-year freedom from reoperation.

Meier freedom from reoperation after PTFE monocusp construction was $96 \%$ at 1 year, $89 \%$ at 5 years, and $82 \%$ at 10 years (Figure 2). Freedom from reoperation in groups I, II, and III at 10 years was $88 \%, 69 \%$, and $90 \%$, respectively. Freedom from reoperation in group II was significantly higher than in group I $(P=.01)$ and group III $(P=.02)$ but was not different between groups I and III.

\section{Late Echocardiographic Follow-up}

The transthoracic echocardiographic studies obtained in the last follow-up ( $>6$ months) were collected on 180 patients. If the patient had been reoperated on for symptomatic RVOT stenosis or regurgitation with RV dilatation, the last echocardiogram performed before reoperation was taken into consideration. Echocardiographic studies before death were also included. One hundred eighty patients had an echocardiogram after a mean follow-up of $4.9 \pm 3.1$ years (range, 6 months to 12 years).

Ventricular dimensions were evaluated in the short axis in 158 patients: the mean ratio between the end-diastolic dimensions of the LV and RV was $0.63 \pm 0.18$. In patients with mild PI, this ratio was smaller than in those with greater than moderate PI $(0.60 \pm 0.14$ vs $0.66 \pm 0.21 ; P=$ $.07)$ but was not significant. Patients who underwent PTFE monocusp reoperation had a larger ratio than the ones who did not require reoperation $(0.60 \pm 0.12$ vs $0.76 \pm 0.29$; $P<.001)$. Excluding the patients who required reoperation, there was no difference $(65.3 \pm 8.7$ vs $63.7 \pm 8.6)$ between patients with trace-to-mild and greater than moderate PI at last follow-up.

The mean RV systolic pressure in all patients was $47.5 \pm$ $16.9 \mathrm{~mm} \mathrm{Hg}$. There was no difference between patients with trace-to-mild and greater than moderate PI at last follow-up $(47.3 \pm 17.0$ and $47.7 \pm 17.0)$, but there was a significant difference between patients who underwent redo surgery and all other patients without reoperation $(71.3 \pm 18.5$ vs $42.1 \pm 10.9 ; P<.0001)$.

The severity of PI was assessed by color Doppler in 180 patients at last follow-up. These results are illustrated in Figure 3. Ninety-four (52\%) had trace-to-mild PI, 73 (41\%) had mild-to-moderate PI, and 13 (7\%) had moderate-tosevere PI. On data obtained 1 year after PTFE monocusp valve insertion, the trace-to-mild degree of PI was detected in $60 \%$ of all patients, with moderate-to severe PI in only in $13 \%$. However, progression of PI was observed at 4 to 5 years with mild-to-moderate PI in $46 \%$ of all cases, which decreased to $35 \%$ at 7 years. The progression of PI to moderate-to-severe PI increased from $15 \%$ to $37 \%$ at 7 years' follow-up. Significant tricuspid regurgitation developed in $6(3 \%)$ patients. The echocardiographic analysis at last follow-up showed that freedom from increased PI greater than moderate was $86 \%$ at 1 year, $68 \%$ at 5 years, and $48 \%$ at 10 years. Freedom from increased PI greater than moderate was $53 \%, 41 \%$, and $49 \%$ at 10 years, respectively. There are no differences between all groups I, II, and III.

The overall peak systolic gradient across the RVOT before PTFE monocusp insertion was $71.2 \pm 21.6 \mathrm{~mm} \mathrm{Hg}$ (range, 16-160 $\mathrm{mm} \mathrm{Hg}$ ) as measured by echocardiography,

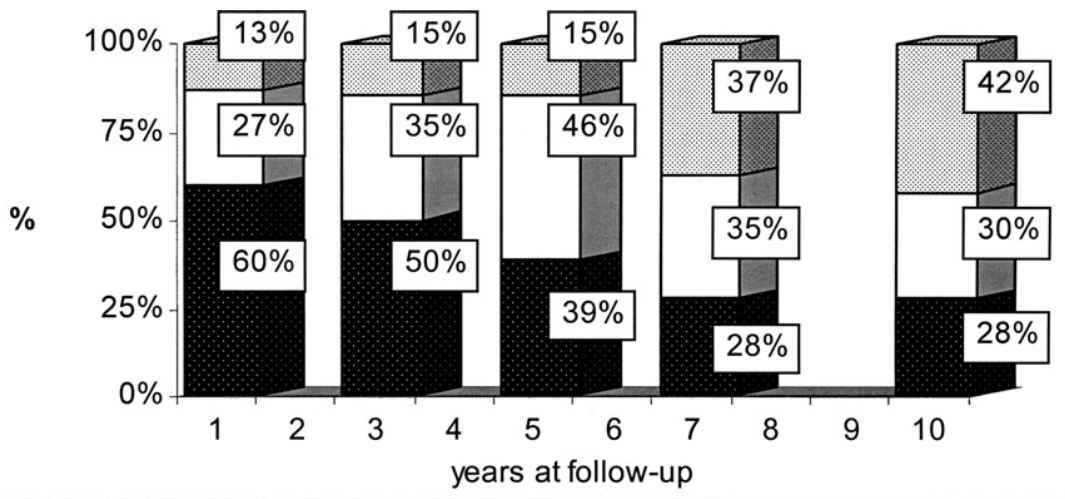

trace-mild

$\square$ mild-moderate

$\square$ moderate-severe

Figure 3. Pulmonary insufficiency detected on follow-up echocardiography. 
and at late follow-up it was $23.1 \pm 12.5 \mathrm{~mm} \mathrm{Hg}(P<$ $.0001)$. Twenty-five (14\%) patients had more than mild-tomoderate stenosis located distal to the monocusp (mean, $44.6 \pm 17.2 \mathrm{~mm} \mathrm{Hg}$ ). Eight of those patients have undergone surgical angioplasty or stent placement of the distal branch PAs.

\section{Discussion}

The operative repair of congenital heart malformations in which the RVOT is severely narrowed often requires incising the annulus of a dysplastic valve and widening of the infundibulum and main PA with a transannular patch to relieve RV pressure overload. Transannular patching, however, leads to marked pulmonary incompetence. ${ }^{12,13} \mathrm{PI}$, when severe and chronic or associated with distal residual obstruction or elevated pulmonary vascular resistance, results in RV failure. Symptomatic RV failure may be delayed for several years and contribute to deterioration in functional status at late follow-up. ${ }^{14,15}$

Conventional techniques to reduce PI at the time of initial repair include bioprosthetic valve insertion, valved conduit insertion, or the creation of a monocusp valve. Allograft conduits were the initial valved conduits used for reconstruction of the RVOT by European surgeons; however, early preservation techniques with antibiotics or irradiation sterilization were associated with early allograft conduit valve failure. ${ }^{16}$ Porcine heterografts mounted in Dacron conduits became available in 1970 in a variety of sizes and were widely used for complex reconstructions in the United States ${ }^{17}$ before cryopreserved allograft conduits became available in the United States during the mid-1980s. Porcine valved Dacron conduits became obstructed with a thick neointimal peel and the valves calcified within 3 to 5 years, and most of the small-diameter conduits became obstructed. Homann and associates ${ }^{18}$ reported that after a period of 10 years, $30 \%$ of children initially receiving allografts and $70 \%$ of patients receiving xenograft conduits had undergone replacement of their initial RV-PA conduits.

The search continues for an ideal RVOT extracardiac conduit. Several centers have advocated using a stented ${ }^{14,17,19,20}$ or nonstented porcine aortic or xenograft pericardial valve mounted inside a pericardial or PTFE tube for patients older than 10 years. We have used both techniques and have found them satisfactory in teenagers and adults. However, the size and rigidity of the valve ring and frame with the stented porcine or pericardial valve reduces the valve orifice area and increases the risk of transmitting sternal compression through the valved conduit to the left main and or left anterior descending coronary artery. The stentless porcine valve as advocated by Kanter and colleagues ${ }^{20}$ has a stiff aortic wall support and eliminates the prosthetic frame and the concern of sternal compression. Absence of a stent allows placement of a valve with a significantly larger valve orifice area. We have recently used several stentless porcine roots (Freestyle; Medtronic, Inc) as an RV-PA conduit, and they have worked well in older children and adults. The stentless aortic root in our opinion is too stiff and noncompliant for infants and younger children and the Freestyle frequently requires addition of a proximal hood to complete the RV connection.

In 1993, Yamagishi and Kurosawa ${ }^{7}$ and Oku and colleagues ${ }^{8}$ independently introduced 0.1-mm PTFE pericardial membrane as a readily available material with good characteristics for monocusp valve construction and compared it with other monocusp leaflet materials. Our animal studies suggested that $0.1-\mathrm{mm}$ PTFE functioned as well as, or better than, fresh or glutaraldehyde-treated pericardium. ${ }^{21}$ Initial clinical application of this technique in patients with TOF resulted in improvement of perioperative RV function, and the technique rapidly gained favor. ${ }^{9}$ It has subsequently been used in more than 200 patients with a wide range of RVOT obstructive and regurgitation defects but is especially valuable in the small infant undergoing primary repair.

The PTFE monocusp with separate RVOT patch has been very useful for our patients with TOF and its variants like VSD with pulmonary atresia who require a transannular patch and in patients requiring a second RVOT procedure after a failed conduit reconstruction (29 patients in this report). The monocusp valve has functioned very well in most patients for the first 2 to 3 years and up to 10 years in some patients, and the monocusp has not produced recurrent RVOT obstruction. Function of the monocusp persists out to 12 years, but some regurgitation develops as the RVOT grows. ${ }^{5,9}$ We believe that the PTFE monocusp reconstruction of a failed allograft conduit is preferable to using a second allograft conduit which, in several series, failed faster that the first allograft. ${ }^{2,22}$ Although the monocusp develops some regurgitation over time, it is better than no valve or a valve that will likely become obstructed, as is seen with allograft and xenograft valves in Dacron RV-PA conduits.

Previous reports in the literature suggesting inconclusive perioperative function and clinical benefit of a PTFE monocusp valve may reflect the challenges of freehand construction or the material chosen for monocusp valve construction. In our series, reconstruction of the RVOT with a PTFE monocusp valve has proven to be a simple and reproducible technique demonstrating excellent early postoperative function with minimal PI. In addition, our results suggest a degree of early clinical benefit in patients in whom a PTFE monocusp valve was used when compared with historic transannular repairs without pulmonary valve reconstruction, ${ }^{9}$ particularly in those with TOF or VSD with pulmonary atresia. The PTFE monocusp valve has also been found to retain a significant degree of competency at mid- 
term follow-up in the TOF group, as well as the group undergoing replacement of the previous RV-PA conduit. As a result, we have favored the PTFE monocusp in both these patient groups. Growth of the RVOT or eventual fibrocollagenous incorporation of the PTFE leaflet may limit longterm function of the monocusp in some patients. The PTFE monocusp valve can be expected to retain adequate function in the early-to-mid postoperative period with the only anticoagulant being low-dose aspirin ( $80 \mathrm{mg}$ per day).

The decision to insert a biologic valved conduit or upsize the PTFE monocusp patch was left up to the individual surgeon and depended on the availability of a suitable conduit. When a pulmonary homograft conduit was the only conduit available, we were more likely to up-size the RVOT with a second PTFE monocusp patch because we thought it would be more durable than the other available conduits at that time. With the introduction of the bovine jugular venous valved conduit (Contegra) in 2001 for clinical trial, we have selectively used the Contegra in some patients who require conduit revision or replacement to see whether the degree of mid-to-late regurgitation is less with the Contegra as compared with the monocusp valve outflow patch. ${ }^{23}$

The current study has the limitations of a retrospective review and has no concurrent control group. Furthermore, magnetic resonance imaging and more refined 2-dimensional and even 3-dimensional echocardiographic studies would have provided additional valuable data regarding evaluation of RV function and dimensions as well as the PTFE monocusp valve mechanics. Exercise testing and assessment of volume of oxygen uptake would better evaluate the functional benefits of this and other RVOT reconstruction techniques. Nevertheless, PTFE monocusp valve reconstruction of the RVOT is a safe, effective, and durable technique for the mid term in the majority of patients and may delay or obviate the need to insert a homograft or xenograft valve in late follow-up. Continued use and long-term follow-up including magnetic resonance imaging and exercise testing is necessary to further demonstrate the value of this technique.

\section{References}

1. Discigil B, Dearani JA, Puga FJ, Schaff HV, Hagler DJ, Warnes CA, et al. Late pulmonary valve replacement after repair of tetralogy of Fallot. J Thorac Cardiovasc Surg. 2001;121:344-51.

2. Niwaya K, Knott-Craig CJ, Lane MM, Chandrasekaren K, Overholt ED, Elkins RC. Cryopreserved homograft valves in the pulmonary position: risk analyses for intermediate-term failure. J Thorac Cardiovasc Surg. 1999;117:141-7.

3. Brown JW, Ruzmetov M, Rodefeld MD, Vijay P, Turrentine MW Right ventricular outflow tract reconstruction with an allograft conduit in non-Ross patients: risk factors for homograft dysfunction and failure. Ann Thorac Surg. 2005;80:655-63.

4. Gundry SR. Pericardial and synthetic monocusp valves: indication and results. Semin Thorac Cardiovasc Surg. 1999;2:77-82.

5. Ando M, Imai Y, Takanashi Y, Hoshino S, Seo K, Terada M. Fate of trileaflet equine pericardial extracardiac conduit used for the correction of anomalies having pulmonic ventricle-pulmonary arterial discontinuity. Ann Thorac Surg. 1997;64:154-8.
6. Bogers AJ, Roofthooft M, Pisters H, Spitaels SE, Bos E. Long-term results of the gamma-irradiation-preserved homograft monocusp for transannular reconstruction of the right-ventricular outflow tract in tetralogy of Fallot. Thorac Cardiovasc Surg. 1994;42:337-9.

7. Yamagishi M, Kurosawa H. Outflow reconstruction of tetralogy of Fallot using a Gore-Tex valve. Ann Thorac Surg. 1993;56:1414-7.

8. Oku H, Matsumoto T, Kitayama H, Ueda M, Saga T, Shirotani H. Semilunar valve replacement with a cylindrical valve. J Card Surg. 1993;8:666-70.

9. Turrentine MW, McCarthy RP, Vijay P, McConnell KW, Brown JW. PTFE monocusp valve reconstruction of the right ventricular outflow tract. Ann Thorac Surg. 2002;73:871-80.

10. Gundry SR, Razzouk AJ, Boskind JF, Bansal R, Bailey LL. Fate of the pericardial monocusp pulmonary valve for right ventricular outflow tract reconstruction. J Thorac Cardiovasc Surg. 1994;107:908-13.

11. Turrentine MW, McCarthy RP, Vijay P, Fiore AC, Brown JW. Polytetrafluoroethylene monocusp valve technique for right ventricular outflow tract reconstruction. Ann Thorac Surg. 2002;74:2202-5.

12. Mishaly D, Birk E, Elami A, Vidne BA. Autologous monocusp pulmonary valve: preliminary results. Ann Thorac Surg. 1996;61:1811-5.

13. Kirklin JK, Kirklin JW, Blackstone EH, Milano A, Pacifico AD. Effect of transannular patching on outcome after repair of tetralogy of Fallot. Ann Thorac Surg. 1989;48:783-91.

14. Danielson GK, Downing TP, Schaff HV, Puga FJ, DiDonato RM, Ritter DG. Replacement of obstructed extracardiac conduits with autogenous tissue reconstructions. J Thorac Cardiovasc Surg. 1987;93: 555-9.

15. Cerfolio RJ, Danielson GK, Warnes CA, Puga FJ, Schaff HV, Anderson $\mathrm{BJ}$, et al. Results of autologous tissue reconstruction for replacement of obstructed extracardiac conduits. J Thorac Cardiovasc Surg. 1995;110:1359-68.

16. Ross DN, Somerville J. Correction of pulmonary atresia with a homograft aortic valve. Lancet. 1966;2:1446-7.

17. Dearani JA, Danielson GK, Puga FJ, Schaff HV, Warnes CW, Driscoll DJ, et al. Late follow-up of 1095 patients undergoing operation for complex congenital heart disease utilizing pulmonary ventricle to pulmonary artery conduits. Ann Thorac Surg. 2003;75:399-411.

18. Homann M, Haehnel JC, Mendler N, Paek SU, Holper K, Meisner H, et al. Reconstruction of the RVOT with valved biological conduits: 25 years experience with allografts and xenografts. Eur J Cardiothorac Surg. 2000;17:624-30.

19. Allen BS, El-Zein C, Cuneo B, Cava JP, Barth MJ, Ilbawi MN. Pericardial tissue valves and Gore-Tex conduits as an alternative for right ventricular outflow tract replacement in children. Ann Thorac Surg. 2002;74:771-7.

20. Kanter KR, Fyfe DA, Mahle WT, Forbess JM, Kirshbom PM. Results with the Freestyle porcine aortic root for right ventricular outflow tract reconstruction in children. Ann Thorac Surg. 2003;76:1889-95.

21. Scavo VA, Turrentine MW, Aufiero TX, Sun K, Binford R, Carlos G, et al. Monocusp valve and transannular patch reconstruction of the right ventricular outflow tract: an experimental study. ASAIO J. 1998; 44:M480-5.

22. Wells WJ, Arroyo H Jr, Bremner RM, Wood J, Starnes VA. Homograft conduit failure in infants is not due to somatic outgrowth. J Thorac Cardiovasc Surg. 2002;124:88-96.

23. Brown JW, Ruzmetov M, Rodefeld MD, Vijay P, Darragh RK. Valved bovine jugular vein conduits for right ventricular outflow tract reconstruction in children: an attractive alternative to pulmonary homograft. Ann Thorac Surg. 2006;82:909-16.

\section{Discussion}

Dr Gordon Cohen (Seattle, Wash). Dr Brown, congratulations on an interesting study, and thank you for sharing your excellent results for this technique with us. The work you presented today represents just one of the many contributions that you and your group have made to our understanding of how to best reconstruct the RVOT in a variety of different congenital defects. After reviewing your study, I have three questions for you. 
First, in the patients who required more than one PTFE monocusp valve, what was the cause of failure and the median and mean time to replacement? In addition, how did you choose in this group of patients whether they would have repeat PTFE monocusp valve replacement versus an RV-PA conduit?

Second, $15 \%$ of the patients had implantation of the PTFE monocusp after RV-PA conduit. Oftentimes when homograft conduits fail, they exhibit shrinkage and calcification. Your own data suggested that there was a mean gradient of $78 \mathrm{~mm} \mathrm{Hg}$ in these gradients consistent with shrinkage, calcification, or outgrowth. How did you decide which patients with previous artery to PA conduits would benefit from a PTFE monocusp valve in this group?

Third, in your slide listing indications for PTFE monocusp redo, you listed 10 patients with trace-to-mild PI as the reason. Many of the valved conduits that we use have trace-to-mild PI immediately after they are placed and the chest is closed. Why would trace-to-mild PI of the PTFE monocusp or any other valve other than for the reason of infection ever be an indication for redo?

Dr Brown. Thank you, Dr Cohen. Those are all excellent questions. To answer your first question, in patients who underwent more than one PTFE monocusp, the cause of failure in almost all situations, as pointed out in the curves, was PI. Only a handful of patients had stenosis.

The second part of that is, how did you choose in which patients you would repeat a PTFE monocusp and in which ones would you use a conduit? To answer that question, if they previously had a conduit, we were not going to put in a second homograft conduit because we know a second homograft conduit fails faster than the first one. Therefore, if a patient had a failed conduit we would put in a PTFE monocusp and then roof that over with another PTFE patch. That is how we decided. However, after 2001, when the Contegra conduit came along, we had a choice of either doing a PTFE monocusp reconstruction of that RVOT or putting in a Contegra conduit. I have to admit our results with the Contegra conduit look pretty promising thus far, and we are leaning in that direction in those whose initial repairs have failed.

To answer your second question, in the $15 \%$ of patients who had PTFE monocusp after RVOT conduits, the answer is almost the same. We continue to try to use the PTFE monocusp in patients in whom it makes sense, but when we have a conduit now that is as good as the Contegra conduit, we are inclined to use more Contegras when a reoperation is necessary. We usually reserve the PTFE monocusp for primary repairs.

Finally, you are absolutely right about the patients with trace PI. That is never an indication for replacement of a conduit or a reconstruction of the RVOT. We just listed those in the slide. Those were the few patients who had significant stenosis. They also had mild PI, but we listed those diagnoses separately. We did not reoperate on patients with trace PI because we know that almost all pulmonary valves, pulmonary conduits, have some leakage early in the postoperative period.

DOCTOR. I would like your comment on a couple issues. Obviously, this is a big issue for congenital heart surgeons. We are replacing the RVOT weekly in our patients. The issue that I have seen, though, is that over the past few years our indications for reinterventions seemed to be changed. Can you comment about that over the time frame of your study?

Second, we are on the verge of these readily deployable percutaneous valve replacements that are probably going to be most successful in the pulmonary outflow tract first before they are deployed in other regions. Does that influence your current reconstruction? In other words, if a 20 -year-old patient is referred to you, what kind of valve replacement do you do so that he or she can be set up for subsequent percutaneous valve replacements?

Dr Brown. Those are both excellent questions. First of all, the way we are deciding to intervene has to do with magnetic resonance imaging. We are studying all of our patients who have dilated RVs with magnetic resonance images, comparing the enddiastolic volumes of the RV with the LV. Right now we are using the Emory formula. If the RV volume is twice that of the LV, we know it is time to intervene even though the patient is asymptomatic because atrial arrhythmias are likely to develop shortly after those ventricles begin to dilate more than that and significant tricuspid insufficiency is likely to occur. We would like to try to intervene before they get those arrhythmias or the tricuspid valve begins to fail. We are doing more RVOT reconstructions than we have ever done in the past and we, like you, are doing them weekly.

Percutaneous pulmonary valves are available in Europe now. More than 110 have been used in London. Yes, we would prefer to put a nonstented valve in the pulmonary position initially because that will make it easier for a stent-deployed valve later on. We are using more stentless valves in the adult patient population. I think there is a little caution here, though, that at least the Contegra conduit is what they use for the stent-mounted valves for the pulmonary position. At least there are some early data that suggest when those valves are mounted inside a stent they do not last nearly as long as if they were surgically implanted. We are going to have to watch that patient population very closely, because I know that at least $10 \%$ of the stent-mounted valves have failed within a 2-year period and we do not see that with a surgically inserted Contegra valve. We will need a little more follow-up. 